CLINICAL STUDY

\title{
Safety of long-term treatment with cabergoline on cardiac valve disease in patients with prolactinomas
}

Renata S Auriemma, Rosario Pivonello, Ylenia Perone, Ludovica F S Grasso, Lucia Ferreri, Chiara Simeoli, Davide Iacuaniello, Maurizio Gasperi ${ }^{1}$ and Annamaria Colao

Sezione di Endocrinologia, Dipartimento di Medicina Clinica e Chirurgia, University 'Federico II', via S. Pansini 5, 80131 Naples, Italy and ${ }^{1}$ Section of Endocrinology, Department of Medicine and Health Sciences, University of Molise, Campobasso, Italy

(Correspondence should be addressed to A Colao; Email: colao@unina.it)

\begin{abstract}
Objective: Cabergoline (CAB) has been found to be associated with increased risk of cardiac valve regurgitation in Parkinson's disease, whereas several retrospective analyses failed to detect a similar relation in hyperprolactinemic patients. The current study aimed at investigating cardiac valve disease before and after 24 and 60 months of continuous treatment with CAB only in patients with hyperprolactinemia.

Subjects and methods: Forty patients (11 men and 29 women, aged $38.7 \pm 12.5$ years) newly diagnosed with hyperprolactinemia entered the study. Cumulative $\mathrm{CAB}$ dose ranged from 12 to $588 \mathrm{mg}$ (median $48 \mathrm{mg}$ ) at 24 months and 48-1260 mg (median $149 \mathrm{mg}$ ) at 60 months. All patients underwent a complete trans-thoracic echocardiographic examination. Valve regurgitation was assessed according to the American Society of Echocardiography.

Results: At baseline, the prevalence of trace mitral, aortic, pulmonic, and tricuspid regurgitations was $20,2.5,10$, and $40 \%$ respectively, with no patient showing clinically relevant valvulopathy. After 24 months, no change in the prevalence of trace mitral $(P=0.78)$ and pulmonic $(P=0.89)$ regurgitations and of mild aortic $(P=0.89)$ and tricuspid $(P=0.89)$ regurgitations was found when compared with baseline. After 60 months, the prevalence of trace tricuspid regurgitation was only slightly increased when compared with that after 24 months $(37.5 \% ; P=0.82)$, but none of the patients developed significant valvulopathy. No correlation was found between cumulative dose and prevalence or grade of valve regurgitation at both evaluations. Prolactin levels normalized in all patients but one.

Conclusion: $\mathrm{CAB}$ does not increase the risk of significant cardiac valve regurgitation in prolactinomas after the first 5 years of treatment.
\end{abstract}

European Journal of Endocrinology 169 359-366

\section{Introduction}

Dopamine agonists (DA) are first-line treatment for patients with both prolactinomas $(1,2)$ and Parkinson's disease (PD) (3). In recent years, there has been an increasing recognition that ergot-derived DA, such as pergolide and cabergoline (CAB), are associated with an increased risk of cardiac valve disease in 29-39\% of patients with $\operatorname{PD}(4,5,6)$, usually treated with mean weekly doses up to $25 \mathrm{mg}$ (7) and taking median cumulative doses ranging from 2600 to $6700 \mathrm{mg}$ (8), with the risk of valvular disease being significantly related to cumulative dose and treatment duration. Particularly, restrictive valvulopathy has been found in $33 \%$ of patients with PD receiving pergolide therapy, but in none of those never treated with DA (4). A few years later, the increased risk of newly diagnosed moderateto-severe valvular regurgitation has been confirmed in patients with $\mathrm{PD}$ treated with pergolide or $\mathrm{CAB}$ when compared with those receiving different antiParkinsonian medications (5, 6). Consequently, in 2007, pergolide has been withdrawn from the US market (9). More recently, in a review of all reports on fibrotic reactions associated with the administration of DA, the US Adverse Event Reporting System database identified 159 cases of clinically relevant valvulopathy in treated patients and $57 \%$ of them were taking CAB (10). Albeit no clear distinction was made between patients with $\mathrm{PD}$ and those with hyperprolactinemia, the authors emphasized that the risk of relevant valvulopathy was significantly dose dependent (10). Moreover, use of DA in patients with PD has been shown to be not associated with an increased risk of newly diagnosed heart failure (11).

Whether treatment with $\mathrm{CAB}$ is associated with an increased risk of clinically significant valvulopathy in patients with prolactinomas is still a matter of debate. A recent nested case-control study (12) has shown in a 
large series that treatment with DA is associated with an increased risk of clinically relevant valve disease (CRVD) in PD but not in hyperprolactinemic patients. Over the past 5 years, 15 independent studies $(13,14,15,16$, $17,18,19,20,21,22,23,24,25,26,27)$ (Table 1) have investigated the effects of $\mathrm{CAB}$ on the development of CRVD in patients with prolactinomas. Overall, these studies have reported a median CRVD rate of $\sim 4 \%$, with the prevalence of CRVD ranging from 54\% (13), 40\% (24), $15 \%(17)$ to $0 \%(15,16,19,21)$ and valvulopathy being assessed according to the International Guidelines suggested by the American Society of Echocardiography $(28,29)$ in all studies and also according to the European Association of Echocardiography $(30,31)$ in ten studies $(13,16,17,18,20,22,23,25,26,27)$. Moreover, a significant correlation between cumulative dose of $\mathrm{CAB}$ and prevalence of valve disease has been demonstrated in only two reports $(13,24)$, whereas the vast majority of studies have agreed on safety of treatment with $\mathrm{CAB}$ on valvulopathy in hyperprolactinemic patients. However, all previous studies are observational and retrospective; prospective studies are still lacking and few data are nowadays available on the effects of $\mathrm{CAB}$ on new-onset relevant valvulopathy in patients with prolactinomas after long-term treatment. The current study aimed at investigating the prevalence and severity of valve regurgitation in patients with prolactinomas before and after 24 and 60 months of continuous treatment with $\mathrm{CAB}$ only.

\section{Subjects and methods}

\section{Inclusion and exclusion criteria}

This prospective study included patients $>18$ years old with a newly established diagnosis of hyperprolactinemia starting treatment with $\mathrm{CAB}$, after the written informed consent with respect to confidentiality statement of data collection according to the Italian privacy policy had been obtained. Exclusion criteria included: i) history of cardiac valve abnormalities, calcifications, or regurgitations associated with annular dilatation or excessive leaflet motion; ii) mitral regurgitation associated with left ventricular all-motion abnormalities or left ventricular dilatation; iii) autoimmune diseases associated with hyperprolactinemia; iv) suspicion of drug or alcohol abuse; v) treatment duration shorter than 12 months; vi) $\mathrm{CAB}$ withdrawal for longer that 1 month; vii) pregnancy occurring while on treatment with $\mathrm{CAB}$; viii) use of DA different from $\mathrm{CAB}$; and ix) denied consent with respect to confidentiality statement of data collection according to the Italian privacy policy.

\section{Patients}

Sixty-nine newly diagnosed consecutive patients with hyperprolactinemia attended the outpatient clinic of Neuroendocrine Disease Unit at 'Federico II' University of Naples between January 1st 2007 and December 31st 2007, with the last patient being recruited on November 29th 2007. Pituitary imaging revealed a microadenoma in 34 patients, a macroadenoma in 27 patients, and nontumoral hyperprolactinemia in eight patients. Twentynine patients were excluded from the analysis because of gestation occurring while on $\mathrm{CAB}$ treatment and requiring therapy discontinuation after a follow-up period shorter than 6 months in eight patients $(11.6 \%$, all with non-tumoral hyperprolactinemia), treatment duration shorter than 12 months in 13 patients $(18.8 \%)$ because of treatment resistance requiring surgery, autoimmune disease in six patients $(8.7 \%)$, and withdrawal of treatment longer than 1 month in two patients $(2.9 \%)$. Therefore, for the purpose of the study, 40 patients (11 men and 29 women, 18 with microadenoma and 22 with macroadenoma), aged $38.7 \pm 12.5$ years, entered the current study. Based on power calculation and sample size

Table 1 Effects of treatment with cabergoline on valvular heart disease in patients with pituitary tumors: overview of the literature.

\begin{tabular}{|c|c|c|c|c|c|c|c|}
\hline $\begin{array}{l}\text { Reference } \\
\text { no. }\end{array}$ & Patient no. & Age (years) & CD (mg) & TD (months) & CRVD (\%) & Valve & $\begin{array}{l}\text { Relation } \\
\text { with CD }\end{array}$ \\
\hline (18) & 102 & $51 \pm 14$ & $18-1718$ & $12-228$ & 2 & Mitral (thickening) & No \\
\hline (15) & 45 & $41 \pm 10$ & $146 \pm 220$ & $39 \pm 29$ & 0 & - & No \\
\hline (17) & 47 & $47 \pm 1$ & $363 \pm 65$ & $62 \pm 5$ & $\begin{array}{r}15 \text { (grade } 3), \\
2 \text { (grade } 4)\end{array}$ & Tricuspid and aortic & No \\
\hline (13) & 50 & $36 \pm 10$ & $414 \pm 390$ & $16-250$ & 54 & Tricuspid & Yes \\
\hline (16) & 44 & $42+13$ & 311 & 44.8 & 0 & - & No \\
\hline (14) & 100 & $41 \pm 13$ & $279 \pm 301$ & $67 \pm 39$ & 7 & - & No \\
\hline (20) & 50 & $51 \pm 2$ & $443 \pm 53$ & $12-156$ & 0 & - & No \\
\hline (19) & 70 & $4 \overline{4}$ & $282 \pm 271$ & $55 \pm 22$ & 5.7 & - & No \\
\hline (21) & 100 & $44 \pm 13$ & $253 \pm 52$ & $48 \pm 4$ & 0 & - & No \\
\hline (22) & 72 & $38(31-49)$ & 126 & $5 \overline{3}$ & 2.7 & Aortic & No \\
\hline (26) & 51 & $42 \pm 13$ & $238.7 \pm 242$ & $12-52$ & 3.9 & Aortic & No \\
\hline (23) & 45 & $48+1.8$ & $401+55$ & 24 & 5 & Mitral and tricuspid & No \\
\hline (25) & 103 & $38 \pm 10$ & $1 \overline{74}$ & $46 \pm 28$ & 2 & Aortic & No \\
\hline (24) & 62 & $37 \pm 10.6$ & $216.2 \pm 306$ & $51 \pm 42$ & 40 & Tricuspid & Yes \\
\hline (27) & 32 & $39 \pm 10$ & 158 & $30-96$ & 6.2 & Tricuspid and aortic & No \\
\hline
\end{tabular}

$C D$, cumulative dose; TD, treatment duration; CRVD, clinically relevant valve disease. 
analysis, a total of 19 patients were required for a statistical power of $80 \%$ at $5 \%$ significance set. The patients' profiles at study entry is shown in Table 2 .

\section{Study protocol}

The present study is prospective in nature. At diagnosis and thereafter at 3- to 6-month intervals as per routine clinical practice, all patients were admitted to the hospital for a complete endocrine screening and physical examination. Once a year, a cardiological visit, an electrocardiography, and an echocardiography were performed. At each clinical examination, blood pressure was measured in the right arm, with the subjects in a relaxed sitting position for $5 \mathrm{~min}$ using a standard mercury sphygmomanometer. Three measurements were taken and averaged to give blood pressure values used in this analysis. If present, systemic arterial hypertension was classified as mild (stage 1) when the systolic and diastolic blood pressure was between 140 and $159 \mathrm{mmHg}$ and between 90 and $99 \mathrm{mmHg}$ respectively; severe (stage 2) when the systolic and diastolic blood pressure was $>160$ and $>100 \mathrm{mmHg}$ respectively; and pre-hypertension was defined as systolic blood pressure between 120 and 139 and diastolic blood pressure between 80 and $89 \mathrm{mmHg}$ (32). Heart rate was also measured. Serum PRL was assessed in all patients at diagnosis and every 3-6 months thereafter, according to our treatment protocol. This study considered three time points: the baseline, the 24-month, and the 60-month evaluation.

\section{Treatment protocol}

According to our previous studies $(1,2,13,33,34,35$, $36,37,38)$, in patients with microprolactinoma and in those with non-tumoral hyperprolactinemia, CAB therapy was administered orally at a starting dose of $0.25 \mathrm{mg}$ twice weekly for the first 2 weeks and then $0.5 \mathrm{mg}$ twice weekly. Dose adjustment was carried out every 3-6 months during our follow-up on the basis of PRL levels. In patients with macroprolactinoma, starting dose was $0.25 \mathrm{mg}$ once a week for the first week and then twice weekly. Dose adjustment was performed at 3- to 6-month intervals as for patients with microprolactinoma or non-tumoral hyperprolactinemia. In patients who did not have normalized PRL levels, CAB dose was progressively

Table 2 Patients' profiles at study entry.

\begin{tabular}{ll}
\hline Patient $(n)$ & 40 \\
Patients' age (years) & $38.7 \pm 12.5$ \\
M/F & $11 / 29$ \\
Microadenoma no. (\%) & $18(45)$ \\
Macroadenoma no. (\%) & $22(55)$ \\
Baseline PRL levels $(\mu \mathrm{g} / \mathrm{l})$ & $789.3 \pm 239.3$ \\
CAB starting dose (mg/week) & $0.25-0.5$ \\
\hline
\end{tabular}

increased up to $5 \mathrm{mg}$ /week. In patients achieving PRL levels $<5 \mu \mathrm{g} / \mathrm{l}$ (the lower limit of normality), CAB dose was reduced to maintain PRL levels in the normal range. Thus, final CAB dose ranged from 0.25 to $5 \mathrm{mg} /$ week. In order to elucidate the role of $\mathrm{CAB}$ dose and duration on echocardiographic findings, the cumulative dose for individual patients was calculated. As doses changed throughout the follow-up, the cumulative dose was the sum of each dose used multiplied for the months of treatment in which that dose was employed. CAB cumulative dose ranged from 12 to $588 \mathrm{mg}$ (median $48 \mathrm{mg}$ ) after 24-month therapy and from 48 to $1260 \mathrm{mg}$ (median $149 \mathrm{mg}$ ) after 60-month follow-up. In order to correlate the rate of valvulopathy with treatment schedule at both evaluations, tertiles of $\mathrm{CAB}$ dose were also calculated and resulted as follows: $<0.5 \mathrm{mg} /$ week = tertile $1,0.51-1.124 \mathrm{mg} /$ week = tertile 2 , and $>1.125 \mathrm{mg} /$ week $=$ tertile 3 at 2 -year follow-up; $<0.9 \mathrm{mg} /$ week $=$ tertile $1,0.91-2.55 \mathrm{mg} /$ week $=$ tertile 2 and $>2.56 \mathrm{mg} /$ week $=$ tertile 3 at 5 -year follow-up.

\section{Echocardiographic study}

At study entry and thereafter once a year, all patients underwent a complete trans-thoracic echocardiographic examination. Echocardiographic examinations were performed in all patients by two experienced cardiologists, blinded to the study participant's data in order to limit any operator bias (39). Both cardiologists worked on the same machine; therefore, technical sensitivity was always identical throughout the study. Standardized operating procedures were used based on international guidelines (40) and monthly meetings were conducted for quality control. The echocardiographic quantitative assessment was performed according to standard methods (41). Recording and measurements of Doppler-derived diastolic function were performed according to the recommendations of the American Society of Echocardiography (28). Pulmonary systolic arterial pressure was estimated by continuous wave Doppler as peak regurgitation velocity plus an assumed right atrial pressure in relation to the size and respiratory excursion of inferior cava vein visualized in subcostal view (42). A cut-off point value of pulmonary arterial systolic pressure of more than $25 \mathrm{mmHg}$ was considered as diagnostic for arterial pulmonary hypertension. Quantification of valvular regurgitation was made according to the recommendations of the American Society of Echocardiography (29). Valve regurgitations were defined and categorized as absent $=$ grade 0 , trace $=$ grade 1 , mild $=$ grade 2 , moderate $=$ grade 3 , and severe $=$ grade 4 . Clinically relevant valve regurgitations were diagnosed when grading was $\geq 3$ for mitral and tricuspid valve and $\geq 2$ for aortic and pulmonic valve (29).

\section{Hormonal assays}

PRL levels were measured by chemiluminescent immunometric assay using commercially available kits 
(Immulite, DPC, Llamberis, UK). The sensitivity was $0.16 \mu \mathrm{g} / \mathrm{l}$; the intra-assay coefficients of variation for PRL concentrations of 22 and $164 \mathrm{ng} / \mathrm{ml}$ were 2.3 and $3.8 \%$ respectively; and the corresponding inter-assay coefficients of variation were $6 \%$. Hyperprolactinemia was defined as a serum PRL level of $>25 \mu \mathrm{g} / \mathrm{l}$ on two different samples more than 1 week apart.

\section{Statistical analysis}

Data were analyzed using SPSS Software for Windows, version 19.0 (SPSS, Inc. package). Data are reported as mean \pm s.D., unless otherwise specified. The comparison between the numerical data before and after treatment with $\mathrm{CAB}$ was made by non-parametric Wilcoxon test. The comparison between prevalence was performed by $\chi^{2}$ test corrected by Fisher exact test when necessary. The correlation study was done by calculating the Pearson's correlation coefficients. Significance was set at $5 \%$.

\section{Results}

The results of the current study are shown in Table 3.

\section{Baseline}

In our patient cohort, baseline PRL levels were 789.3 $\pm 239.3 \mu \mathrm{g} / \mathrm{l}$. The prevalence of mitral, aortic, pulmonic, and tricuspid valve regurgitations was $20,2.5,10$, and
40\% respectively (Fig. 1). Among patients, none had CRVD at study entry. Grading is detailed in Table 3.

\section{4-Month evaluation}

At a median cumulative dose of $48 \mathrm{mg}$ (range: 12-588 mg), PRL levels were significantly reduced by $94 \%$ as overall $(P=0.003$, Table 3$)$ compared with baseline evaluation and resulted fully normalized in all patients but one. No patient developed moderate or severe valve insufficiency, and none had arterial pulmonary hypertension. When compared with baseline, a slight but not significant increase was found in the prevalence of trace mitral $(17.5 \mathrm{vs} 22.5 \%, P=0.78)$ and pulmonic ( 10 vs $12.5 \%, P=0.89$ ) valve regurgitations and of mild tricuspid ( 5 vs $7.5 \%, P=0.89$ ) and aortic (0 vs $2.5 \%, P=0.89$ ) valve regurgitations, with the latter being found only in one hypopituitaric male patient affected with arterial hypertension and with evidence of new-onset aortic root dilatation and fibrosis at the echocardiographic examination. According to dose tertiles, 20 patients $(50 \%)$ were in the first tertile, ten $(25 \%)$ in the second tertile, and ten $(25 \%)$ in the third tertile. Mitral and pulmonic valve insufficiency occurred in 60 and $40 \%$ of patients in the second tertile and in $40 \%(P=0.6)$ and $10 \%(P=0.3)$ of those in the third tertile respectively. Similarly, tricuspid valve regurgitation was recorded in $35 \%$ of patients in the first tertile, $60 \%(P=0.36)$ in the second tertile, and $40 \%(P=0.89)$ in the third tertile.

Table 3 Effects of treatment with CAB on disease control and on development of clinically relevant valve disease in our patient cohort.

\begin{tabular}{|c|c|c|c|c|c|c|}
\hline & Baseline $(A)$ & 24 Months (B) & 60 Months $(C)$ & $\boldsymbol{P}(\mathrm{A}$ vs $\mathrm{B})$ & $\boldsymbol{P}$ (B vs C) & $\boldsymbol{P}(\mathrm{A}$ vs $\mathrm{C})$ \\
\hline PRL levels $(\mu \mathrm{g} / \mathrm{l})$ & $789.3 \pm 239.3$ & $13.6 \pm 22.4$ & $3.4 \pm 6.5$ & 0.003 & 0.003 & $<0.001$ \\
\hline CAB cumulative dose/mg (range) & - & $48(12-588)$ & $149(4 \overline{8}-1260)$ & - & - & - \\
\hline \multicolumn{7}{|l|}{ Mitral valve regurgitation (\%) } \\
\hline Total & 20 & 25 & 25 & 0.79 & 1 & 0.79 \\
\hline Trace & 17.5 & 22.5 & 22.5 & 0.78 & 1 & 0.78 \\
\hline Mild & 2.5 & 2.5 & 2.5 & 1 & 1 & 1 \\
\hline Severe & 0 & 0 & 0 & - & - & - \\
\hline \multicolumn{7}{|l|}{ Aortic valve regurgitation (\%) } \\
\hline Total & 2.5 & 5 & 5 & 0.92 & 1 & 0.92 \\
\hline Trace & 2.5 & 2.5 & 2.5 & 1 & 1 & 1 \\
\hline Mild & 0 & 2.5 & 2.5 & 0.89 & 1 & 0.89 \\
\hline Moderate & 0 & 0 & 0 & - & - & - \\
\hline Severe & 0 & 0 & 0 & - & - & - \\
\hline \multicolumn{7}{|l|}{ Pulmonic valve regurgitation (\%) } \\
\hline Trace & 10 & 12.5 & 12.5 & 0.89 & 1 & 0.89 \\
\hline Mild & 0 & 0 & 0 & - & - & - \\
\hline Moderate & 0 & 0 & 0 & - & - & - \\
\hline Severe & 0 & 0 & 0 & - & - & - \\
\hline \multicolumn{7}{|l|}{ Tricuspid valve regurgitation (\%) } \\
\hline Total & 40 & 42.5 & 45 & 0.89 & 0.82 & 0.78 \\
\hline Trace & 35 & 35 & 37.5 & 1 & 0.89 & 0.89 \\
\hline Mild & 5 & 7.5 & 7.5 & 0.89 & 1 & 0.89 \\
\hline Moderate & 0 & 0 & 0 & - & - & - \\
\hline Severe & 0 & 0 & 0 & - & - & - \\
\hline
\end{tabular}




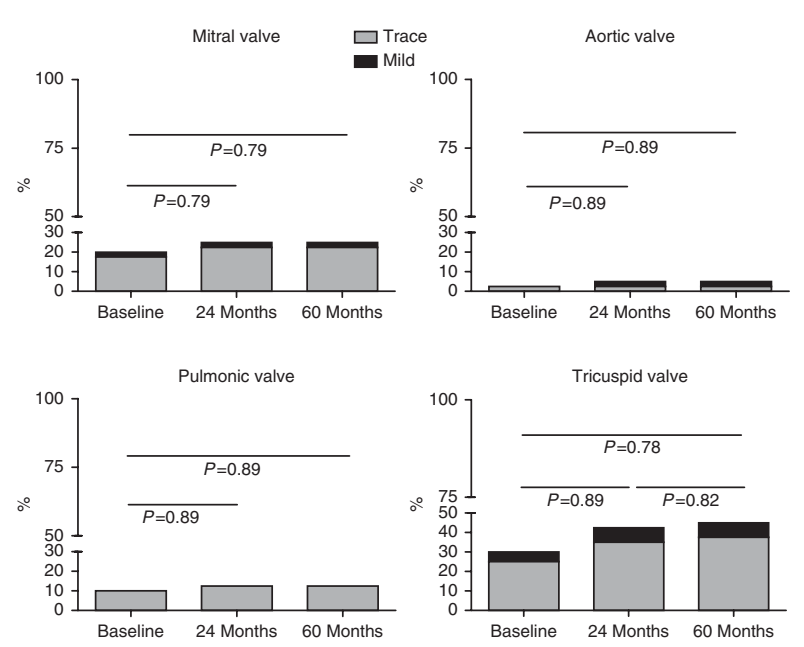

Figure 1 Prevalence and severity of cardiac valve regurgitations in the present series of prolactinomas at baseline and after 24 and 60 months of treatment with CAB. A slight but not significant increase was found in both rate and grading of valve insufficiency after 2 and 5 years of therapy with CAB. Mild aortic insufficiency occurred in only one patient (2\%) after 24 months of treatment, whereas moderate or severe mitral, tricuspid, and pulmonic regurgitations did not occur in the current patient cohort after 24 or 60 months of follow-up.

\section{0-Month evaluation}

At a median cumulative dose of $149 \mathrm{mg}$ (range: $48-1260 \mathrm{mg}$ ), PRL levels were significantly lower than 24-month evaluation by $75 \% \quad(P=0.003$, Table 3), with complete normalization in all patients but one. As at 24-month evaluation, among patients none developed moderate or severe valve insufficiency, and none showed arterial pulmonary hypertension. As shown in Table 3, after 60 months of treatment, only the prevalence of tricuspid valve regurgitation was found further slightly but not significantly increased compared with 24 months ( 42.5 vs $45 \%, P=0.82$ ) and baseline ( 40 vs $45 \%, P=0.78$ ), with trace tricuspid valve regurgitation being $37.5 \%(P=0.89)$. No further impairment of both aortic root dilatation and fibrosis or aortic regurgitation was observed in the hypopituitaric male with severe arterial hypertension who continued $\mathrm{CAB}$ therapy. According to dose tertiles, 24 patients $(60 \%)$ were in the first tertile, nine $(22.5 \%)$ in the second tertile, and seven $(17.5 \%)$ in the third tertile. Mitral valve insufficiency occurred in $25 \%$ of patients in the first tertile, $22 \%(P=0.78)$ of those in the second tertile, and $28.6 \%(P=0.76)$ in the third tertile. Similarly, tricuspid valve regurgitation was recorded in $29 \%$ of patients in the first tertile, $66 \%(P=0.12)$ in the second tertile, and in $71 \%(P=0.11)$ in the third tertile. Pulmonic insufficiency was found in $44 \%$ of patients in the second tertile and $11 \%(P=0.37)$ in the third tertile. Compared with short-term evaluation, prevalence of each valve insufficiency did not significantly change after long-term treatment with $\mathrm{CAB}$ (Fig. 2). Particularly, a slight but not significant increase was found in the prevalence of mitral regurgitation ( 0 vs $25 \%$, $P=0.27$ ) in tertile 1 , pulmonic ( 40 vs $44 \%, P=0.72$ ) and tricuspid (60 vs $66 \%, P=0.84$ ) regurgitations in tertile 2 , and tricuspid regurgitation (40 vs $71 \%$, $P=0.47$ ) in tertile 3 (Fig. 2). Prevalence of tricuspid regurgitation in tertile 1 ( 35 vs $29 \%, P=0.92$ ) and of mitral regurgitation in tertile $2(60$ vs $22 \%, P=0.23)$ and in tertile 3 ( 40 vs $28.6 \%, P=0.9$ ) were found even slightly reduced after 60-month $\mathrm{CAB}$ when compared with short-term evaluation (Fig. 2).

\section{Correlation study}

After 24 months of treatment with CAB, no significant correlation was found between either median cumulative dose and prevalence of mitral $(r=-0.19$, $P=0.26)$, aortic $(r=-0.15, P=0.38)$, pulmonic $(r=-0.10, P=0.55)$, and tricuspid $(r=-0.18$, $P=0.29)$ valve or grading of mitral $(r=-0.19$, $P=0.26)$, aortic $(r=-0.14, P=0.40)$, pulmonic $(r=-0.08, P=0.60)$, and tricuspid $(r=-0.09$, $P=0.59)$ valve insufficiency. Similarly, at 60 -month follow-up, no significant correlation was found between either median cumulative dose and prevalence of mitral $(r=-0.18, P=0.29)$, aortic $(r=-0.11$,
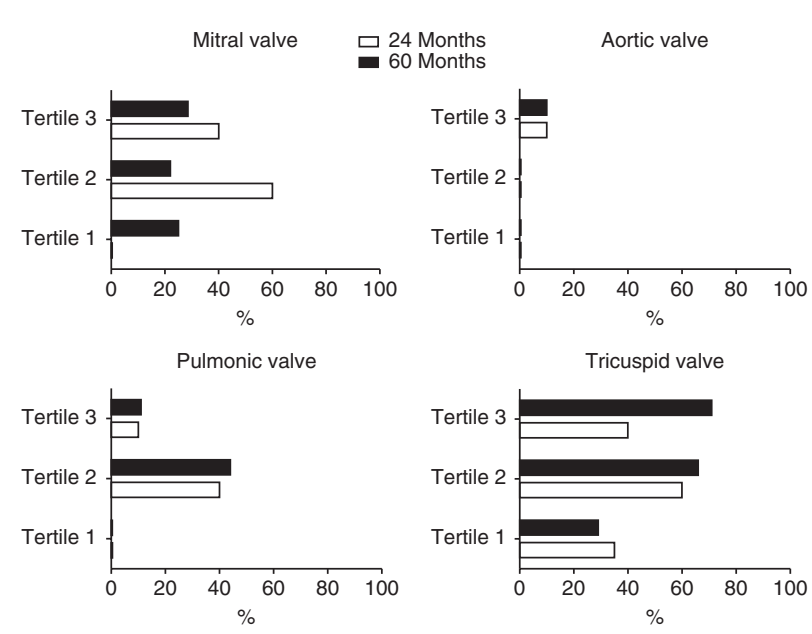

Figure 2 Prevalence of mitral (upper left panel), aortic (upper right panel), pulmonic (bottom left panel), and tricuspid (bottom right panel) valve regurgitations in each tertile of $C A B$ dose after 24 (white bars) and 60 (black bars) months of treatment with CAB. Compared with short-term evaluation, prevalence of each valve insufficiency did not significantly change after long-term treatment with $\mathrm{CAB}$. Particularly, a slight but not significant increase was found in the prevalence of mitral regurgitation ( 0 vs $25 \%, P=0.27$ ) in tertile 1, pulmonic ( 40 vs $44 \%, P=0.72$ ) and tricuspid ( 60 vs $66 \%$, $P=0.84$ ) regurgitations in tertile 2 , and tricuspid regurgitation (40 vs $71 \%, P=0.47$ ) in tertile 3 (Fig. 2). Prevalence of tricuspid regurgitation in tertile 1 (35 vs $29 \%, P=0.92$ ) and of mitral regurgitation in tertile 2 ( 60 vs $22 \%, P=0.23$ ) and in tertile 3 ( 40 vs $28.6 \%, P=0.9$ ) were even slightly reduced after 60 -month $\mathrm{CAB}$ when compared with short-term evaluation. 
$P=0.53)$, pulmonic $(r=-0.01, P=0.93)$, and tricuspid $(r=-0.10, P=0.55)$ valve or grading of mitral $(r=-0.20, P=0.24)$, aortic $(r=-0.11, P=0.53)$, pulmonic $(r=-0.01, P=0.93)$, and tricuspid $(r=-0.08, P=0.65)$ valve regurgitations. At both evaluations, no correlation was found between dose tertiles and valve regurgitation $(r=-0.1, P=0.56)$.

\section{Discussion}

This is the first prospective study to demonstrate that treatment with $\mathrm{CAB}$ does not increase the risk of clinically relevant valve regurgitation in patients with prolactinomas after the first 5 years of treatment. The DA-induced valve damage has been hypothesized to be mediated by the serotoninergic system because these drugs have been demonstrated to have high affinity for the serotonin receptor subtype $2 \mathrm{~B}$, which is abundantly expressed in heart valves and is known to promote mitogenesis $(43,44)$. CAB and pergolide are reportedly potent agonists of these receptors, whereas other dopaminergic agents, including bromocriptine and lisuride, have antagonistic properties (44).

Results from 15 observational studies investigating the risk of fibrotic valvulopathy in hyperprolactinemic patients treated with $\mathrm{CAB}$ have been published to date $(13,14,15,16,17,18,19,20,21,22,23,24,25,26$, $27)$. Two of them $(15,20)$ have shown no relevant findings. Four studies $(16,18,21,24)$ have demonstrated an increased prevalence of non-clinically relevant valve regurgitations, including mild tricuspid regurgitation $(16,21,24)$, pulmonic insufficiency (16), or enlarged mitral tenting area (18). Ten trials $(13,14$, $17,18,19,22,23,25,26,27)$ have reported a variable prevalence, ranging from $2 \%$ (25) to $54 \%$ (13), of relevant valvulopathy including moderate-to-severe mitral or tricuspid insufficiency and mild aortic regurgitation, with the latter being observed only in two investigations $(22,24)$. Overall, a median CRVD rate of $\sim 4 \%$ has been reported in hyperprolactinemic patients receiving treatment with $\mathrm{CAB}$. In line with Delgado et al. (23), reporting no change in prevalence and grading of cardiac valve disease after 2-year treatment, the results of the current prospective study demonstrate no significant increase in the risk of CRVD after both 24 and 60 months of treatment with CAB. Moreover, even though trivial valvulopathy was slightly increased after long-term treatment, the overall prevalence of mitral (25\%) and tricuspid (45\%) valvular regurgitations has been found to be not increased when compared with the general population, in line with the results of the Framingham Heart Study (45), showing an overall prevalence of any degree of mitral and tricuspid regurgitations in $88-91$ and $82-86 \%$ of the general population respectively. In our series, the prevalence of mild aortic insufficiency $(2.5 \%)$ was similar to the $2.7 \%$ reported by Tan et al. (22), the $2 \%$ recorded by Elenkova et al. (25), and the 3.9\% found by Córdoba-Soriano et al. (26) and within the 0-14\% described in the general population (45). In our cohort of patients, none developed significant pulmonic regurgitation or arterial pulmonic hypertension, and none showed moderate or severe regurgitation of mitral and tricuspid valve. These findings disagree with our previous data (13), showing a high prevalence (54\%) of moderate tricuspid regurgitation in CABtreated hyperprolactinemic patients. Particularly, we reported an approximately three times higher relative risk to develop moderate tricuspid valve regurgitation in treated patients compared with healthy controls and de novo patients (13). Interestingly, the increased prevalence of tricuspid insufficiency was found to be not associated with age, BMI, or blood pressure values but significantly CAB dose dependent (13), as already reported in patients with PD (14). In fact, moderate valve regurgitation was significantly more prevalent in patients who had been treated with a cumulative dose above the median $(280 \mathrm{mg}, 72 \%)$ than in those receiving lower doses $(36 \%, P=0.023)$. It is noteworthy that patients with moderate tricuspid regurgitation had higher systolic and diastolic blood pressure when compared with those with no evidence of relevant valvulopathy (13). However, some important differences between the current results and our previous findings should be highlighted. In this study, median cumulative dose of $\mathrm{CAB}$ at both 2-year $(48 \mathrm{mg})$ and 5-year evaluations (149 mg) was lower than that in our previous observation $(280 \mathrm{mg})$ and much lower than that in patients with PD, usually treated with mean weekly doses up to $25 \mathrm{mg}(7)$ and taking median cumulative doses ranging from 2600 to $6700 \mathrm{mg}$ (8). Secondly, in our previous study (13), follow-up ranged from 16 to 250 months (median 74 months), whereas in the current prospective study, follow-up reached 60 months of observation. Albeit in patients with hyperprolactinemia, treatment duration has not been associated with the prevalence or severity of valvulopathy, and significant valvulopathy reportedly occurred more frequently in patients with PD after long-term treatment (5). Moreover, our previous data supported that tricuspid tethering area was significantly wider in treated patients than in controls and de novo patients (13). As previously shown in patients with PD $(10,46)$, $\mathrm{CAB}$ may induce subclinical fibrotic alterations in valve architecture predisposing to severe dysfunctions. The increased prevalence of subclinical regurgitations in hyperprolactinemic patients treated with $\mathrm{CAB}$ described in some reports $(17,18)$ would be consistent with this observation. Particularly, in the series by Kars et al. (17), mitral and aortic calcifications as well as leaflet thickening of the tricuspid valve were reported. Similarly, Lancellotti et al. (18) described mitral leaflet thickening in 6 of 102 patients receiving $\mathrm{CAB}$ and found that mitral tenting area, a quantitative index of valve restriction, was significantly higher in patients with mild 
valvulopathy than in controls. We did not observe leaflet thickening in any patient, but after 24 months of therapy, the echocardiographic evaluation recorded aortic root dilatation and fibrosis only in a 61-year-old man $(2 \%)$ affected with poorly controlled stage 2 arterial hypertension and with hypopituitarism on replacement therapy. Interestingly, this patient required high-dose treatment ( $5 \mathrm{mg}$ ) after 39 months of follow-up because of a partial resistance to medical therapy, but mild aortic fibrosis and dysfunction were diagnosed after 2-year therapy at a weekly dose of $1.5 \mathrm{mg}$.

In conclusion, the results of the current prospective study demonstrate that long-term $\mathrm{CAB}$ is not associated with an increased risk of CRVD in patients with prolactinomas. Nevertheless, besides the profibrotic effect largely and extensively described in patients with PD, several clinical conditions, including older age, systemic arterial hypertension, and gender, may increase the rate and severity of cardiac valve damage in patients with hyperprolactinemia. Therefore, in such patients, a careful echocardiographic investigation is mandatory. Further studies are needed to extend and confirm these data.

\section{Declaration of interest}

The authors declare that there is no conflict of interest that could be perceived as prejudicing the impartiality of the research reported.

\section{Funding}

This study did not receive any specific grant from any funding agency in the public, commercial, or not-for-profit sector.

\section{Acknowledgements}

This paper has been registered by A C in the www.clinicaltrials.gov database with the ID NCT00460616.

\section{References}

1 Biller BMK, Colao A, Petersenn S, Bonert VS \& Boscaro M. Prolactinomas, Cushing's disease and acromegaly: debating the role of medical therapy for secretoty pituitary adenomas. BMC Endocrine Disorders 201010 10. (doi:10.1186/1472-6823-10-10)

2 Gillam MP, Molitch ME, Lombardi G \& Colao A. Advances in the treatment of prolactinomas. Endocrine Reviews 200627 485-534. (doi:10.1210/er.2005-9998)

3 Nutt JG \& Wooten GF. Diagnosis and initial management of Parkinson's disease. New England Journal of Medicine 2005353 1021-1027. (doi:10.1056/NEJMcp043908)

4 Van Camp G, Flamez A, Cosyns B, Weytjens C, Muyldermans L \& Van Zandijcke M. Treatment of Parkinson's disease with pergolide and relation to restrictive valvular heart disease. Lancet 2004363 1179-1183. (doi:10.1016/S0140-6736(04)15945-X)

5 Schade R, Andersohn F, Suissa S, Haverkamp W \& Garbe E. Dopamine agonists and the risk of cardiac-valve regurgitation. New England Journal of Medicine 2007356 29-38. (doi:10.1056/ NEJMoa062222)

6 Zanettini R, Antonini A, Gatto G, Gentile R, Tesei S \& Pezzoli G. Valvular heart disease and the use of dopamine agonists for Parkinson's disease. New England Journal of Medicine 2007356 39-46. (doi:10.1056/NEJMoa054830)
7 Valassi E, Klibanski A \& Biller BMK. Potential cardiac valve effects of dopamine agonists in hyperprolactinemia. Journal of Clinical Endocrinology and Metabolism 201095 1025-1033. (doi:10.1210/jc.2009-2095)

8 Kars M, Pereira AM, Bax JJ \& Romijn JA. Cabergoline and cardiac valve disease in prolactinoma patients: additional studies during long-term treatment are required. European Journal of Endocrinology 2008159 363-367. (doi:10.1530/EJE-08-0611)

9 March 29, 2007 FDA Public Health Advisory: pergolide. Available on: http://www.fda.gov/Drugs/DrugSafety/PublicHealthAdvisories/ ucm051192.htm (accessed 26 ${ }^{\text {th }}$ October 2012).

10 Andersohn F \& Garbe E. Cardiac and noncardiac fibrotic reactions caused by ergot- and nonergot-derived dopamine agonists. Movement Disorders 200924 129-133. (doi:10.1002/mds. 22385)

11 Mokhles MM, Trifirò G, Dieleman JP, Haag MD, van Soest EM, Verhamme KM, Mazzaglia G, Herings R, Luise Cd, Ross D et al. The risk of new onset heart failure associated with dopamine agonist use in Parkinson's disease. Pharmacological Research 2012 65 358-364. (doi:10.1016/j.phrs.2011.11.009)

12 Trifirò G, Mokhles MM, Dieleman JP, van Soest EM, Verhamme K, Mazzaglia G, Herings R, de Luise C, Ross D, Brusselle G et al. Risk of cardiac valve regurgitation with dopamine agonist use in Parkinson's disease and hyperprolactinaemia: a multi-country, nested case-control study. Drug Safety 201235 159-171. (doi:10.2165/11594940-000000000-00000)

13 Colao A, Galderisi M, Di Sarno A, Pardo M, Gaccione M, D'Andrea M, Guerra E, Pivonello R, Lerro G \& Lombardi G. Increased prevalence of tricuspid regurgitation in patients with prolactinomas chronically treated with cabergoline. Journal of Clinical Endocrinology and Metabolism 200893 3777-3784. (doi:10.1210/jc.2007-1403)

14 Bogazzi F, Buralli S, Manetti L, Raffaelli V, Cigni T, Lombardi M, Boresi F, Taddei S, Salvetti A \& Martino E. Treatment with low doses of cabergoline is not associated with increased prevalence of cardiac valve regurgitation in patients with hyperprolactinemia. International Journal of Clinical Practice 200862 1864-1869. (doi:10.1111/j.1742-1241.2008.01779.x)

15 Devin JK, Lakhani VT, Byrd BF III \& Blevins LS Jr. Prevalence of valvular heart disease in a cohort of patients taking cabergoline for management of hyperprolactinemia. Endocrine Practice 2008 14 672-677. (doi:10.4158/EP.14.6.672)

16 Wakil A, Rigby AS, Clark AL, Kallvikbacka-Bennett A \& Atkin SL. Low dose of cabergoline for hyperprolactinemia is not associated with clinically significant valvular heart disease. European Journal of Endocrinology 2008159 R11-R14. (doi:10.1530/EJE08-0365)

17 Kars M, Delgado V, Holman ER, Feelders RA, Smit JW, Romijn JA, Bax JJ \& Pereira AM. Aortic valve calcification and mild tricuspid regurgitation, but no clinical heart disease after 8 years of dopamine agonist therapy for prolactinomas. Journal of Clinical Endocrinology and Metabolism 200893 3348-3356. (doi:10.1210/jc.2007-2658)

18 Lancellotti P, Livadariu E, Markov M, Daly AF, Burlacu MC, Betea D, Pierard L \& Beckers A. Cabergoline and the risk of valvular lesions in endocrine disease. European Journal of Endocrinology 2008159 1-5. (doi:10.1530/EJE-08-0213)

19 Vallette S, Serri K, Rivera J, Santagata P, Delorme S, Garfield N, Kahtani N, Beauregard H, Aris-Jilwan N, Houde G et al. Long-term cabergoline therapy is not associated with valvular heart disease in patients with prolactinomas. Pituitary 200912 153-157. (doi:10.1007/s11102-008-0134-2)

20 Herring N, Szmigielski C, Becher H, Karavitaki N \& Wass JA. Valvular heart disease and the use of cabergoline for the treatment of prolactinomas. Clinical Endocrinology 2009 70 104-108. (doi:10.1111/j.1365-2265.2008.03458.x)

21 Nachtigall L, Valassi E, Lo J, Mc Carty D, Passeri J, Utz A, Biller BMK, Miller KK \& Klibanski A. Gender effects on cardiac valvular function in hyperprolactinaemic patients receiving cabergoline: a retrospective study. Clinical Endocrinology 2009 72 53-58. (doi:10.1111/j.1365-2265.2009.03608.x) 
22 Tan T, Cabrita IZ, Hensman D, Grogono J, Dhillo WS, Baynes KC, Eliahoo J, Meeran K, Robinson S, Nihoyannopoulos P et al. Assessment of cardiac valve dysfunction in patients receiving cabergoline treatment for hyperprolactinaemia. Clinical Endocrinology 201073 369-374. (doi:10.1111/j.1365-2265. 2010.03827.x)

23 Delgado V, Biermasz NR, van Thiel SW, Ewe SH, Marsan NA, Holman ER, Feelders RA, Smit JW, Bax JJ \& Pereira AM. Changes in heart valve structure and function in patients treated with dopamine agonists for prolactinomas, a 2-year follow-up study. Clinical Endocrinology 201277 99-105. (doi:10.1111/j.13652265.2011.04326.x)

24 Halperin I, Aller J, Varela C, Mora M, Abad A, Doltra A, Santos AE, Batista E, Garcia-Pavia P, Sitges M et al. No clinically significant valvular regurgitation in long-term cabergoline treatment for prolactinomas. Clinical Endocrinology $2012 \mathbf{7 7}$ 275-280. (doi:10.1111/j.1365-2265.2012.04349.x)

25 Elenkova A, Shabani R, Kalinov K \& Zacharieva S. Increased prevalence of subclinical cardiac valve fibrosis in patients with prolactinomas on long-term bromocriptine and cabergoline treatment. European Journal of Endocrinology 2012167 17-25. (doi:10.1530/EJE-12-0121)

26 Córdoba-Soriano JG, Lamas-Oliveira C, Hidalgo-Olivares VM, Tercero-Martínez A, Barambio-Ruíz M \& Salas-Nieto J. Valvular heart disease in hyperprolactinemic patients treated with low doses of cabergoline. Revista Española de Cardiología 201366 $410-412$.

27 Boguszewski CL, dos Santos CM, Sakamoto KS, Marini LC, de Souza AM \& Azevedo M. A comparison of cabergoline and bromocriptine on the risk of valvular heart disease in patients with prolactinomas. Pituitary 201215 44-49. (doi:10.1007/s11102011-0339-7)

28 Quinones MA, Otto CM, Stoddard M, Waggoner A, Zoghbi WA \& Doppler Quantification Task Force of the Nomenclature and Standards Committee of the American Society of Echocardiography . Recommendations for quantification of Doppler echocardiography: a report from the Doppler Quantification Task Force of the Nomenclature and Standards Committee of the American Society of Echocardiography. Journal of the American Society of Echocardiography 200215 167-184. (doi:10.1067/mje.2002.120202)

29 Zoghbi WA, Enriquez-Sarano M, Foster E, Grayburn PA, Kraft CD, Levine RA, Nihoyannopoulos P, Otto CM, Quinones MA, Rakowski $\mathrm{H}$ et al. Recommendations for evaluation of the severity of native valve regurgitation with two-dimensional and Doppler echocardiography. Journal of the American Society of Echocardiography 200316 777-802. (doi:10.1016/S0894-7317(03) 00335-3)

30 Lang RM, Bierig M, Devereux RB, Flachskampf FA, Foster E, Pellikka PA, Picard MH, Roman MJ, Seward J, Shanewise J et al. Recommendations for chamber quantification. European Journal of Echocardiography 20067 79-108. (doi:10.1016/j.euje.2005. 12.014)

31 Authors/Task Force Members, Vahanian A, Baumgartner H, Bax J, Butchart E, Dion R, Filippatos G, Flachskampf F, Hall R, Iung B et al. Guidelines on the management of valvular heart disease: The Task Force on the Management of Valvular Heart Disease of the European Society of Cardiology. European Heart Journal $2007 \mathbf{2 8}$ 230-268. (doi:10.1093/eurheartj/ehl428)

32 Chobanian AV, Bakris GL, Black HR, Cushman WC, Green LA, Izzo JL Jr, Jones DW, Materson BJ, Oparil S, Wright JT Jr et al. The Seventh Report of the Joint National Committee on Prevention, Detection, Evaluation, and Treatment of High Blood Pressure: the JNC 7 report. Hypertension 200342 1206-1252. (doi:10.1161/ 01.HYP.0000107251.49515.c2)

33 Colao A, Di Sarno A, Landi ML, Cirillo S, Sarnacchiaro F, Facciolli G, Pivonello R, Cataldi M, Merola B, Annunziato L et al. Long-term and low-dose treatment with cabergoline induces macroprolactinoma shrinkage. Journal of Clinical Endocrinology and Metabolism 199782 3574-3579. (doi:10.1210/jc.82.11.3574)
34 Colao A, Di Sarno A, Landi ML, Scavuzzo F, Cappabianca P, Pivonello R, Volpe R, Di Salle F, Cirillo S, Annunziato L et al. Macroprolactinoma shrinkage during cabergoline treatment is greater in naïve than in patients pre-treated with other dopamine agonists: a prospective study in 110 patients. Journal of Clinical Endocrinology and Metabolism $2000 \quad 85$ 2247-2252. (doi:10.1210/jc.85.6.2247)

35 Di Sarno A, Landi ML, Cappabianca P, Di Salle F, Rossi FW, Pivonello R, Di Somma C, Faggiano A, Lombardi G \& Colao A. Resistance to cabergoline as compared with bromocriptine in hyperprolactinemia: prevalence, clinical definition and therapeutic strategy. Journal of Clinical Endocrinology and Metabolism 200186 5256-5261. (doi:10.1210/jc.86.11.5256)

36 Colao A, Sarno AD, Cappabianca P, Briganti F, Pivonello R, Somma CD, Faggiano A, Biondi B \& Lombardi G. Gender differences in the prevalence, clinical features and response to cabergoline in hyperprolactinemia. European Journal of Endocrinology 2003148 325-331. (doi:10.1530/eje.0.1480325)

37 Di Sarno A, Landi ML, Marzullo P, Di Somma C, Pivonello R, Cerbone G, Lombardi G \& Colao A. The effect of quinagolide and cabergoline, two selective dopamine receptor type 2 agonists, in the treatment of prolactinomas. Clinical Endocrinology $2000 \mathbf{5 3}$ 53-60. (doi:10.1046/j.1365-2265.2000.01016.x)

38 Colao A, Di Sarno A, Sarnacchiaro F, Ferone D, Di Renzo G, Merola B, Annunziato L \& Lombardi G. Prolactinomas resistant to standard dopamine agonists respond to chronic cabergoline treatment. Journal of Clinical Endocrinology and Metabolism 1997 82 876-883. (doi:10.1210/jc.82.3.876)

$39 \mathrm{Gu}$ H, Luck S, Carroll PV, Powrie J \& Chambers J. Cardiac valve disease and low-dose dopamine agonist therapy: an artefact of reporting bias? Clinical Endocrinology 2011 74 608-610. (doi:10.1111/j.1365-2265.2010.03973.x)

40 Popescu BA, Andrade MJ, Badano LP, Fox KF, Flachskampf FA, Lancellotti P, Varga A, Sicari R, Evangelista A, Nihoyannopoulos P et al. European Association of Echocardiography recommendations for training, competence, and quality improvement in echocardiography. European Journal of Echocardiography 200910 893-905. (doi:10.1093/ejechocard/jep151)

41 Sahn DJ, De Maria A, Kisslo J \& Weyman A. Recommendations regarding quantitation of M-mode echocardiography: results of a survey of echocardiographic measurements. Circulation $1978 \mathbf{5 8}$ 1072-1083. (doi:10.1161/01.CIR.58.6.1072)

42 Pepi M, Tamborini G, Galli C, Barbier P, Doria E, Berti M, Guazzi M \& Fiorentini C. A new formula for echo-Doppler estimation of right ventricular systolic pressure. Journal of the American Society of Echocardiography 19947 20-26.

43 Redfield MM, Nicholson WJ, Edwards WD \& Tajik AJ. Valve disease associated with ergot alkaloid use: echocardiographic and pathologic correlations. Annals of Internal Medicine 1992117 50-52. (doi:10.7326/0003-4819-117-1-50)

44 Jahnichen S, Horowski R \& Pertz HH. Agonism at 5-HT2B receptors is not a class effect of the ergolines. European Journal of Pharmacology 2005513 225-228. (doi:10.1016/j.ejphar.2005.03.010)

45 Singh JP, Evans JC, Levy D, Larson MG, Freed LA, Fuller DL, Lehman B \& Benjamin EJ. Prevalence and clinical determinants of mitral, tricuspidal, and aortic regurgitation (the Framingham Heart Study). American Journal of Cardiology 199983 897-902. (doi:10.1016/SO002-9149(98)01064-9)

46 Antonini A \& Poewe W. Fibrotic heart-valve reactions to dopamineagonists treatment in Parkinson's disease. Lancet Neurology 20076 826-829. (doi:10.1016/S1474-4422(07)70218-1)

Received 21 March 2013

Revised version received 13 May 2013

Accepted 1 July 2013 